\title{
Designing for Pre-Fabrication and Assembly in the Construction of UBC's Tall Wood Building
}

\author{
Azadeh FALLAHI $^{1 *}$, Erik A. POIRIER ${ }^{2}$, Sheryl STAUB-FRENCH ${ }^{3}$ \\ Javier GLATT ${ }^{4}$ and Nicholas SILLS ${ }^{5}$ \\ ${ }^{1}$ MASc candidate, Department of Civil Engineering, University of British Columbia \\ ${ }^{2}$ Postdoctoral Fellow, Department of Civil Engineering, University of British Columbia \\ ${ }^{3}$ Associate Professor, Department of Civil Engineering, University of British Columbia Co- \\ ${ }^{4}$ Founder and CEO, CADMakers inc, Canada \\ ${ }^{5}$ Detailing Supervisor, Structurlam Products LP, Canada \\ *Corresponding author's e-mail: Azadeh.fallahi@gmail.com
}

\begin{abstract}
The construction of a $53 \mathrm{~m}, 18$ story mass timber high-rise on the Vancouver campus of the University of British Columbia poses significant challenges in its design, approval, procurement and construction. As a way to facilitate the project delivery process, the project team called upon extensive use of virtual design and construction (VDC) and building information modelling (BIM) that are supported through a $3^{\text {rd }}$ party VDC service provider. One of the key uses of BIM and VDC in the project is extensive design for pre-fabrication and assembly of mass timber elements and envelope panels as well as mechanical elements. The processes, techniques and tools used to support design for pre-fabrication and assembly on the UBC Tall Wood Building project are presented in this paper. The challenges and lessons learned in the deployment and use of these tools and processes and their impact on project delivery are also discussed. Lastly, the trade-offs and design considerations that support design for pre-fabrication and assembly are examined. Initial findings indicate that the design for pre-fabrication and assembly process is a highly involved and collaborative process which requires the presence of key decision makers up front in the project delivery process. They also indicate that the involvement of a $3^{\text {rd }}$ party BIM and VDC modeller, using highly sophisticated digital tools, is necessary to ensure proper information flow and capture relating to the elements being designed for pre-fabrication and assembly. Ultimately, in the context of mass timber high-rise construction, where competitive advantage over other approaches resides in speed and quality of execution, aesthetic and sustainability concerns notwithstanding, designing for pre-fabrication and assembly is key in ensuring the project's economic viability.
\end{abstract}

\section{KEYWORDS}

Virtual design and construction, Building information modelling, Design for pre-fabrication, mass timber, high rise construction 


\section{INTRODUCTION}

As a response to the 2013 Natural Resources Canada (NRCan) and Canadian Wood Council (CWC)'s request for an Expression of Interest (EOI) for identifying building projects in Canada that can demonstrate the commercial viability of innovative wood building solutions in high-rise construction, the UBC Brock Commons Phase 1 project also known as the UBC Tall Wood project was presented and selected as one of the three demo projects in (CWC). This building is a $53 \mathrm{~m}$, 18 story building which employs a hybrid timber-concrete structural system and will house 404 students in single and quad units on each floor.

Due to the many design and construction constraints highlighted later in figure 2, from the design development stages, the understanding with the project team had been to use pre-fabrication as much as possible and to keep the budget at a minimum. This method of designing for a set goal early on is called design for $\mathrm{X}$ and there are a variety of techniques associated with it. Design for assembly and manufacturing (DFA \& DFM) focuses on minimizing cost of product development and manufacturing (Holt) and the proffered method of applying DFA is through systematic methods for analysing assemblies (Moultrie). Using BIM in aiding the prefabrication process is becoming exceedingly common in China where clash detection and constructability analysis are done from initial design stages to ensure the prefabrication is efficient and cost effective (Zhang).

This paper looks at the processes and strategies involved in designing and constructing the prefabricated elements used on site through interviews with the designers and trades as well as the author's knowledge from having been involved in the pre-planning and design through construction stages.

\section{DESIGN PROCESS}

From inception, the understanding has been "the structure would be substantially unique, the envelope would be somewhat unique and the interior finishes would be relatively typical" (Olund) which led to an iterative sequential design process which would pick out the structural system based on cost effectiveness and feasibility and optimize the envelope to fit the structural system.

A 3-day workshop was held very early on in the process (January 2015) with the presence of the Owner, the Architect, Structural Engineer, Code Consultant, Construction Manager, Virtual Construction Integrator, Wood Erection and Concrete trade in order to develop the design and optimize the cost to prove the baseline target of $192 \$ / \mathrm{ft}^{2}$ could be achieved. The following items were built into the cost models and once the budgets were established and the prices were determined to be appropriate, the $3 \mathrm{~d}$ modeler took the hand sketches provided by the structural engineers to produce $3 \mathrm{~d}$ models which were later turned to $2 \mathrm{~d}$ cad drawings used by the structural designers to further analyze their design and ensure the adequacy:

- Materials: Taken off the $3 \mathrm{~d}$ model being developed throughout the session

- Equipment: From the construction manager's experience as well as the breakdown for the proxy concrete building

- Labour: Estimated through contributions and collaborations of the present trades and designers (Olund) 


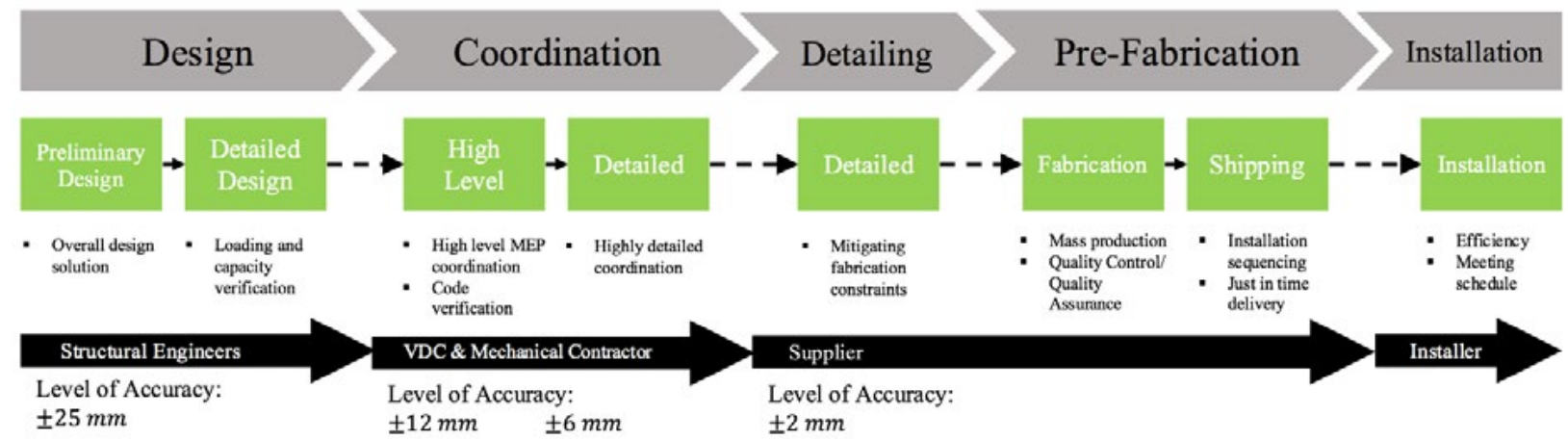

Figure 1. Hand off, Constraints, Responsibility and Tolerances Process Map

\section{USE OF VDC}

Virtual design and construction has been used extensively on this project since the pre-construction and design development stages and covered a wide range of purposes including (Poirier):

- Visualization

- Inter-disciplinary coordination

- Clash detection

- Constructability review

- Quantity takeoff

- 4D Planning

- Sequencing

- Digital fabrication of Prefabricated mock up elements

- Structural analysis

Having a fully detailed model from the early stages of the design development has allowed the whole design team to make decisions faster and with higher certainty by removing several layers of risks associated with not having a comprehensive picture of the final product in mind for everyone involved. The high degree of BIM and VDC often means more opportunities for offsite pre-fabrication. In order for the developed model to be fully functional for the pre-fabrication purposes, keeping the model alive and up to date with the latest changes is of utmost importance. Having a third party VDC integrator has allowed for that to happen as the responsibility of the up keep is well established.

The VDC integrator uses CATIA V6 for their detailed modeling which is a software developed by Dassault Systèmes mainly for the aerospace industry. The fact that CATIA allows for parametric modeling means that each change in the design and dimensions of any particular element will get translated into changes for the entire building. This again reduces risk of re-work, change orders or clashes on the construction site.

Having a third party VDC integrator has also allowed for higher trade buy-in and has helped throughout the stages of tendering to construction planning meetings. Since the model developed includes every trade's elements, a "big picture" idea of the final product is shown to the trades before arrival on site and has helped identify possible congestion and double utilization of 
resources on site as well as establishing installation sequences and optimizing it. The sequence has been established by holding trade meetings with the presence of all the trades as well as the VDC integrator representative that shows a $4 \mathrm{D}$ model $\left(4^{\text {th }}\right.$ dimension being sequencing, not necessarily schedule) that collects feedback that informs both the modelers and the trades. Table 1 presents the various software used by the pre-fabrication team for their purposes:

Table 1. The Various Software Used by Project Team

\begin{tabular}{|c|c|c|c|}
\hline Discipline & Use & Software Name & Parent Company \\
\hline \multicolumn{4}{|l|}{ VDC Integrator } \\
\hline & Detailed 3d modelling & CATIA V6 & Dassault Systèmes \\
\hline & $\begin{array}{l}\text { Clash Detection and } \\
\text { Coordination }\end{array}$ & ENOVIA V6 & Dassault Systèmes \\
\hline & $\begin{array}{l}\text { 4D Modeling }+ \text { Sequencing } \\
\text { Videos }\end{array}$ & DELMIA V6 & Dassault Systèmes \\
\hline Timber suppliers & $\begin{array}{c}\text { Shop drawings, Clash } \\
\text { Detection, CNC Coding, } \\
\text { Tolerance Tuning }\end{array}$ & cadwork & $\begin{array}{c}\text { cadwork } \\
\text { informatic } A G\end{array}$ \\
\hline
\end{tabular}

\section{PRE-FABRICATION}

Due to many constraints both in design and in constructability of the project, the necessity of heavy use of pre-fabrication has been apparent to the entire design team from the beginning. The constraints that led to this decision can be grouped into the following categories:

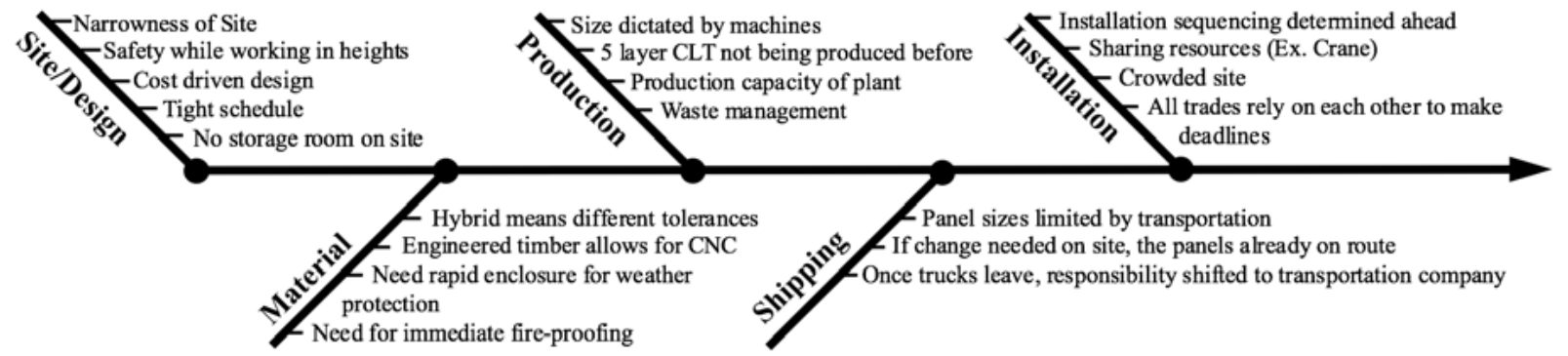

Figure 2. Constraints in pre-fabrication

The prefabricated elements of the site can be grouped into the following 3 main groups:

\section{Mass Timber Elements}

The mass timber pre-fabricated parts are grouped into the glulam/PSL columns and the cross laminated timber (CLT) floor panels. The building was designed to not have any beams as to address the $53 \mathrm{~m}$ height restriction and since all the MEP has to be hung from the ceiling. In determining the structural system, the structural engineers used an elimination approach to settle on the selected 2-way slab and column option. The timber supplier modified and updated their 5 layer panels from their typical product library to meet the design requirements and had to become PRG 320 certified with the APA to be accepted for submission. The prefabricated timber parts include close to 1,300 glulam/PSL columns and 464 CLT floor panels. As it will be discussed later 
in this paper, a proof of concept mockup building was built during the design development stage which led to the decision of including the steel connections inside of the timber supplier's scope of work to ensure more stringent quality control measures can be taken at the fabrication plant and meet the desired tolerance for the timber pieces which is $\pm 2 \mathrm{~mm}$.

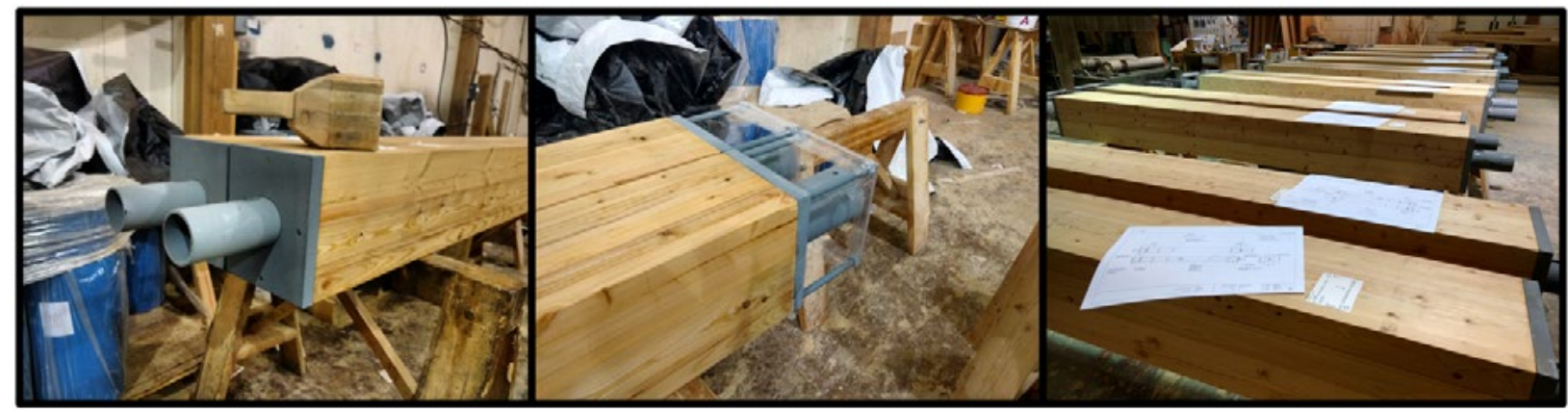

Figure 3. Glulam columns with the steel connections installed offsite

The CLT panels rest on steel angels that are welded to the concrete cores and have steel drag straps at the perimeter of the floor and at some that connect back to the core to increase stiffness and take on the lateral loads. The columns have an HSS connection which enables them to rest on the top of the columns from the floors below at the bottom and have the CLT panels rest on them at the top.

The VDC integrator coordinated heavily with the structural designers and the timber suppliers to ensure their model is kept updated at all times with the latest tolerances and production considerations such as blade thickness, drilling tolerances and etc. built in so the exported geometry would require minimum processing before being fed to the $\mathrm{CNC}$ machines. In order to increase efficiency on site and facilitate meeting schedule mile stones, the VDC integrator worked closely with the MEP contractors to build all the ducts, electrical risers and plumbing holes into the model and have them be pre-drilled offsite. Once built, the panels are loaded on to the trucks in the reverse order of installation to further increase the installation speed. Determining the agreed upon sequencing and installation considerations was made possible by holding meeting in which the VDC integrator would show videos of proposed installation sequences and incorporate the acquired feedback of the present erector, supplier and construction manager into an updated and final loading plan and sequence numbering.

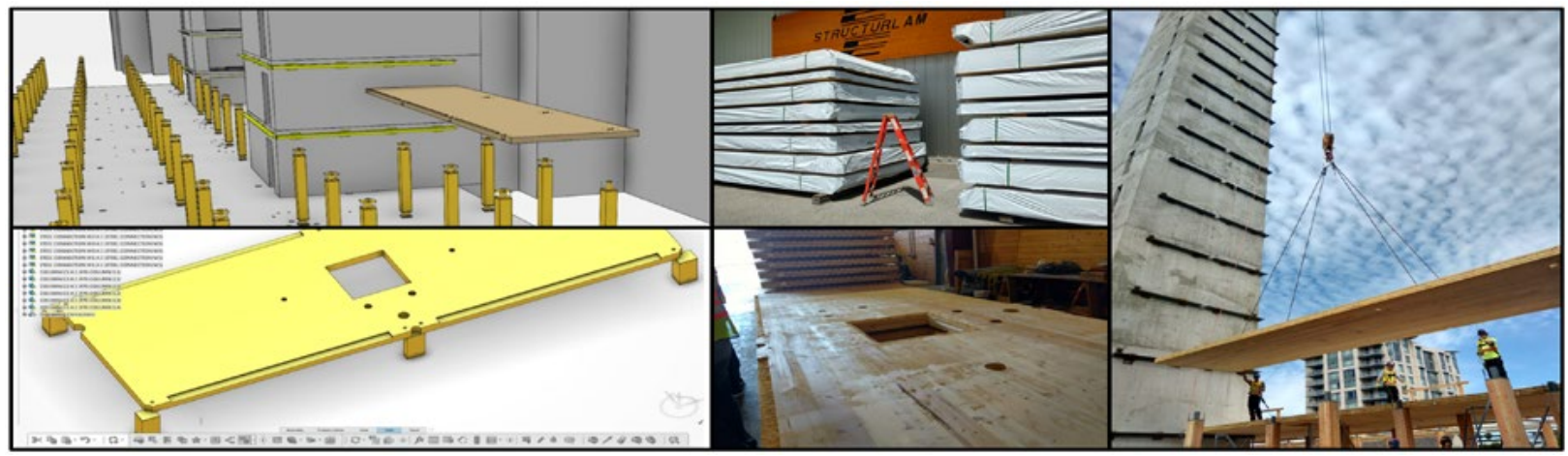

Figure 4. CLT panel design, fabrication and installation 


\section{Envelope Panels}

The panels were to be tendered as a "design-build" package and through the mock-up stage, and the understanding was that the successful trade would design, fabricate and install it. 4 different types of panels were proposed which included a wood frame option, a carbon fibre reinforced precast concrete option and a structural steel stud system with pre-installed windows, out of which the latter was successful. In choosing the winning system the items that were looked at were weight, cost and ease of installation as well as satisfying the non-combustible construction concerns (Poirier). Another constraint while designing the envelope system was to ensure the stiffness of the panels to prevent buckling due to their size while being lifted up on site and to ensure structural adequacy of the panels to take on the gravity loads of the envelope panels themselves that should transfer those loads down.

The selected system includes an exterior rain screen cladding system up to the steel studs and further batt insulations, vapor barrier and interior drywall will be installed on site. The panels one floor high by 8 metres long which corresponds to two structural bays. They are connected to the building at the top through steel L angles located at the perimeter of the timber floors using 4-5 bolts depending on the size of the panels and are connected at the bottom to the lower slab using a female-male interlock. In developing the prefabricated panel, the owner insisted on a price per square feet that was typical of a project of this size and type and effectively did not allow for a cost of innovation for the panels and the envelope panels were tendered at only $8.5 \%$ higher than the price initially required by the owner. The understanding from the beginning had been that when designed and tested and proved by constructing this project, the envelope fabricator has effectively created a new product and with it can have a large new market for buildings that require rapid construction regardless of their structural system (Poirier).

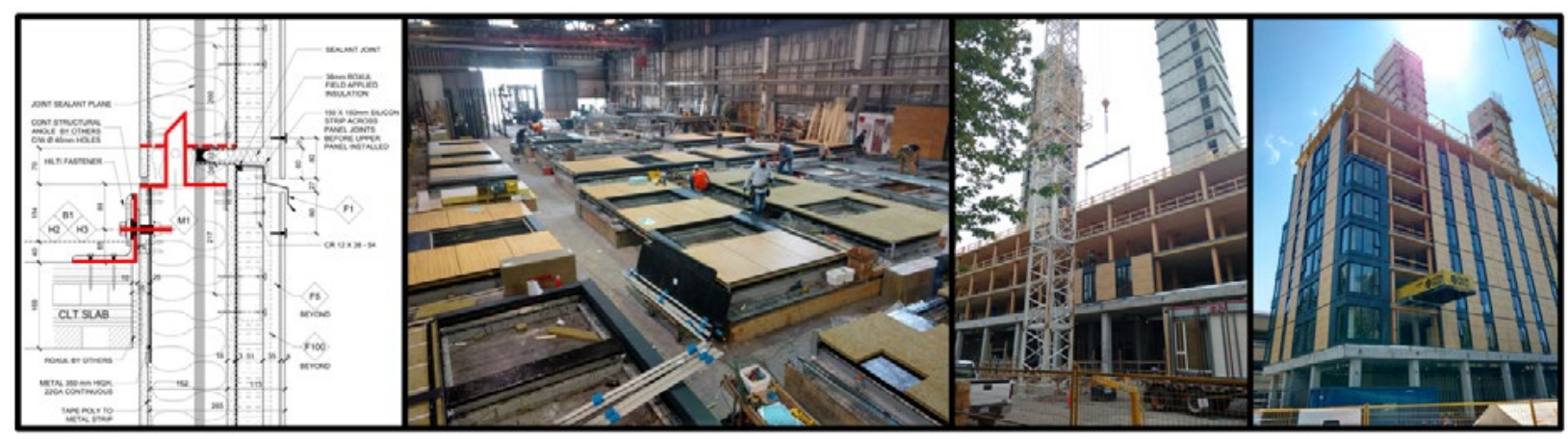

Figure 5. Envelope connections, fabrication and installation

\section{Mechanical Elements}

In order for the use of timber to make economic sense in this project, the speed of erection once the timber portion starts were of utmost importance. Since timber can achieve that, the more time consuming trades need to keep with the pace so as to meet the schedule. One of areas identified by the design team with prefab opportunities was the mechanical and plumbing systems. Since heavy coordination with MEP was required by the VDC integrators to ensure the CLT floor penetrations were precise and ready for off-site drilling, a much heavier level of detail than traditional buildings were required much earlier in the design phase. It is customary for the MEP designer to layout a general plan and have the mechanical trade figure out the details on site, 
however in this project, the mechanical trade was brought on board during the design stages and plumbing routings were finalized in order to finish the floor panel drawings. The VDC integrators sat down with a plumber for 7-8 sessions of 2-3 hours long each to finalize the details. They then generated spool drawings that outline the exact lengths, dimensions and locations of spools to be fabricated off-site and be brought on as groups. This resulted in only 2 spool packages being configured for 17 residential floors (one for studio units and one for quads) which captured a lot of value from an economy of scale perspective. Additionally, the entirety of the mechanical room was designed to be prefabricated and built on site in a fraction of the time of that of a typical building.

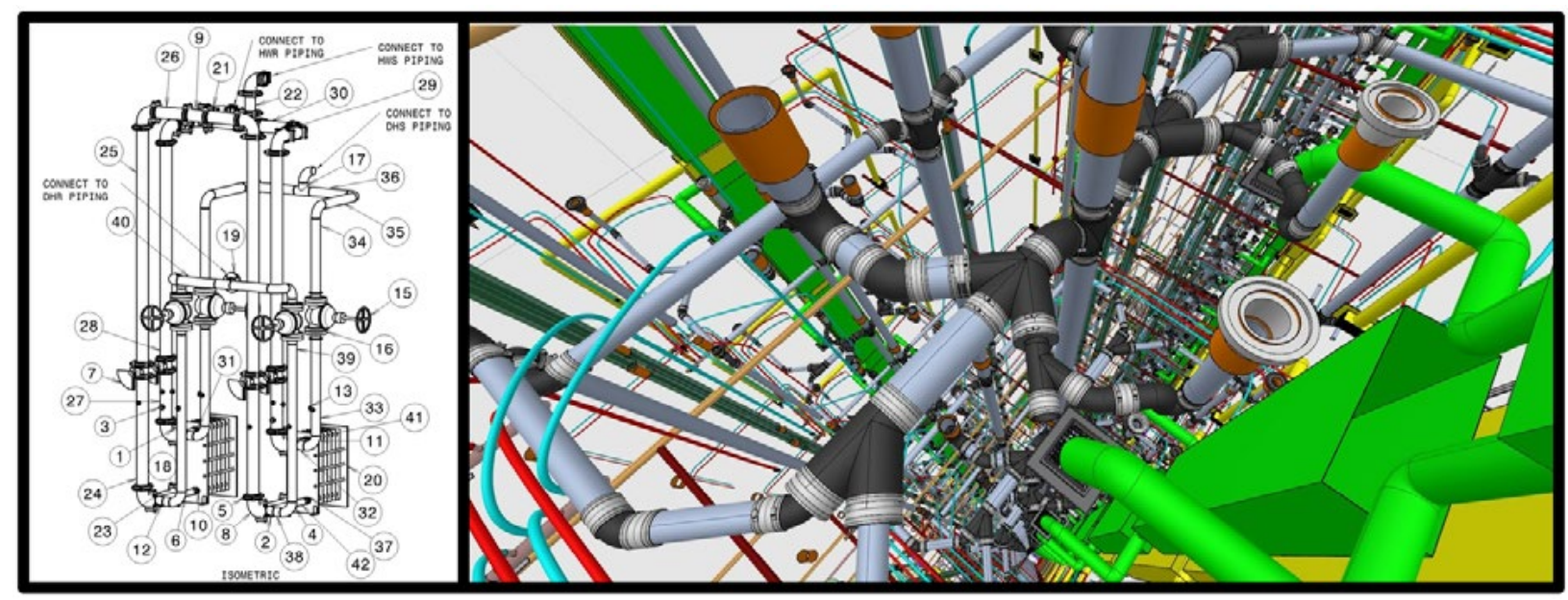

Figure 6. The Detailed Plumbing and Mechanical Modeling-Snap shot of Pre-fab Spools

\section{PROOF OF CONCEPT MOCK-UP}

In order to prove the viability of the prefabricated elements including the floor panels, the glulam columns and the envelope panels, a full scale mock-up funded by UBC properties Trust was constructed in Abbotsford BC during the design stages of the project. Cording to the UBC PT project manager, the building needed a test run, or a practice, to ensure the details would perform and work as well as it was required.

During the mock-up construction, the flow of information between the timber supplier and the VDC integrator was put to the test. At that time, the VDC integrator created shop drawing-like documents with detailed dimension and tolerance instructions and submitted to the timber supplier. They then created their own drawings readable by their machines and constructed the panels and the columns. One issue that was highlighted during that stage was the steel connections of the main timber structure was outside the scope of the timber suppliers which led to coordination and quality control issue. It was taken as a lesson learned and the steel connections are now included in the timber supplier contract package in which they have a sub-supplier but they are in charge of assembling and doing quality control for the connections before arrival to site. 


\section{CONCLUSION}

Currently, the construction is still underway and the final verifications of the performances need to happen in order to comment on the success of the project. That said, the construction site and the installation times are as planned and the expectation is the building will complete a minimum of 2 months earlier than a replica of this building using concrete and its typical construction methods. The current speed of erection is 2 floors per week and even though there are possibilities of increasing that to 3 floors per week, since the other trades including concrete for the acoustical topping, fire graded gypsum board trade for covering every part of the exposed timber, interior finishing and other trades need to catch up and share some of the resources including the crane, the erection speed is to stay as is for now.

There have been many lessons learned both throughout the pre-planning stages and the mock-up construction stage that has informed many of the decisions made further in the process as well in any other future projects, including other phases of the Brock Commons project:

- Extensive use of the VDC: Due to very tight tolerances and precisions required to build a hybrid structure, detailed coordination was key and VDC was the perfect tool as the idea is to fully construct the building down to every bolt and nut.

- Heavy pre-planning: Even though many of the trades present during the preliminary design stages did not have a contract at the time of the workshop, their presence provided valuable feedback that dictated the direction of the design which later translated to better understanding of the project as a whole for all trades.

- Reliability of prefabrication: For this project, the pre-fabrication trades were required to work with much tighter tolerances than they are used to but in the end, due to the controlled environment of a fabrication plant, precisions beyond anything that can be achieved on a construction site are realized.

- Trade buy-in: Open and clear communication throughout the bidding and hiring process of the trades were key in ensuring the trades have a clear idea of their scope and responsibilities to avoid over or underestimation that can lengthen the schedule and incur extra costs.

\section{REFERENCES}

Canadian Wood Council, "A Request for An Expression Of Interest To Design And Construct A 10 Storey Or Taller High Rise Wood Demonstration Project(S) In Canada". Cwcdemoproject.ca. N.p., 2013. Web. 10 July 2016.

Holt, Raymond and Catherine Barnes. "Towards An Integrated Approach To "Design For X": An Agenda For Decision-Based DFX Research". Res Eng Design 21.2 (2009): 123-136. Web. 10 July 2016.

Moultrie, James and Anja M. Maier. "A Simplified Approach To Design For Assembly". Journal of Engineering Design 25.1-3 (2014): 44-63. Web. 10 July 2016.

Olund, Brent and Javier Glatt. "Brock Commons-Virtual Design and Construction". 2016. Presentation.

Poirier, Erik et al. UBC Tall Wood Building Case Study (Design And Pre-Construction Phase). 2016. Print. Reported To Forestry Innovation Investment.

Zhang, Jinyue et al. "BIM-Enabled Modular And Industrialized Construction In China".

Procedia Engineering 145 (2016): 1456-1461. Web. 9 July 2016. 